\title{
A alma, o olho, a mão ou o uso da autobiografia no teatro
}

\section{Resumo}

Marcia Abujamra ${ }^{1}$

O texto faz uma aproximação entre a figura do narrador, segundo Walter Benjamin, e a de atores/ performers que criam seus espetáculos a partir de um material autobiográfico, uma aproximação entre a experiência compartilhada por narrador/performer e ouvinte/público. Para contextualizar essa discussão, apresenta-se o trabalho do performer americano Spalding Gray, referência quando se pensa no uso da autobiografia.

Palavras-chave: Autobiografia; Performance; Spalding Gray

\section{Abstract}

The text establishes a connection between the figure of the narrator, according to Walter Benjamin, and actors/performers who create their own pieces from an autobiographical material; a connection between the experience shared by narrator/performer and listener/audience. In order to contextualize this discussion, I present the work of the american performer Spalding Gray, a reference when one thinks about the use of autobiography.

Keywords: Autobiography; Performance; Spalding Gray

\section{Resumen}

El texto establece un acercamiento entre las figuras del narrador, según Walter Benjamin, y de actores/ performers que crean sus espectáculos a partir de un material autobiográfico; una aproximación entre la experiencia compartida por el narrador/performer y el oyente/público. Para contextualizar esta discusión, presento la obra del performer estadounidense Spalding Gray, referencia con respecto al uso de la autobiografía.

Palabras claves: Autobiografia; Performance; Spalding Gray

O uso da autobiografia no universo das artes cênicas é um fenômeno recente e crescente ${ }^{2}$ e recoloca uma das questões mais antigas do teatro: a relação - ou,

1 É doutoranda do Programa de Artes Cênicas/ Pedagogia do Teatro pela Universidade de São Paulo, com orientação de Elisabeth Silva Lopes. É diretora de teatro, produtora e roteirista.

2 Alguns dos textos que exploram essa ideia são: FISCHER-LICHTE, Erika. "Reality and fiction in contemporary theatre". In BOROWSKI, Mateusz e SUGÍERA, Malgorzata, Fictional realities/real fictions. Newcastle, Cambridge Scholars Publishing, 2007; FÉRAL, Josette. "Le réel à 'epreuve du théâtre". In FÉRAL, Josette. Théorie et pratique du théâtre. Au-delà des limites. Paris, L'Entretemps, 2011; FINTER, Helga. "A teatralidade e o teatro. Espetáculo do real ou realidade do espetáculo? Notas sobre a teatra- lidade e o teatro recente na Alemanha". Teatro al Sur, n. 25, out. 2003; DA COSTA, José. "Irrupções do real no teatro contemporâneo". Subtexto, Belo Horizonte, n.6, dez 2009; GUMBRECHT, Hans Ulrich. Produção de Presença. O que o sentido não consegue transmitir. Trad. Ana Isabel Soares. RiodeJaneiro: Contraponto: Ed. PUC-Rio, 2010. CORNAGO, Óscar. "Bio-drama. Sobre El teatro dela vida y la vida del teatro. Latin American Theatre Review, (39):1, 2005, entre muitos outros artigos e livros. 
segundo Erika Fischer-Lichte, a tensão ${ }^{3}$ - entre realidade e ficção, entre o real e o fictício.

Durante longo tempo, essa relação teve como foco a ficção, criada a partir de vários mecanismos: a construção de personagens oriundos de um texto dramatúrgico por atores que, de posse de diferentes técnicas interpretativas, tentam fazer desaparecer seus corpos e personalidades com o objetivo maior de dar vida a esses personagens; um espaço real que representa diferentes espaços fictícios; um tempo cênico que não corresponde ao tempo da vida cotidiana. Se essa ficção esteve em foco em grande parte da história do teatro, a partir dos anos de 1960 esse interesse se alterou. Segundo Fischer-Lichte, um dos primeiros criadores responsáveis por essa inversão foi Jerzy Grotowski:

Nos anos 60, o foco mudou do fictício para o real, sem que a tensão entre eles diminuisse. Não foi apenas a performance art, mas também artistas como Jerzy Grotowski a enfatizarem o real na performance. [...] Grotowski inverteu a relação entre ator e personagem, entre o real e o ficcional. Ele definia o personagem fictício como um instrumento para se atingir um objetivo específico, e não como o objetivo final do esforço do ator. Como um cirurgião usa seu bisturi, ao ator é pedido que use o personagem como uma ferramenta para dissecar a si mesmo."

O uso de material autobiográfico é visto como um desenvolvimento/desdobramento da presença do real no teatro. Nesse artigo, vou me concentrar no teatro e não na presença do real em outras manifestações, como a performance art (Marina Abramovic, Chris Burden, Orlan, entre tantos outros) ou o cinema, com a crescente valorização do documentário. No teatro, os exemplos de que dispomos para ilustrar essa presença em sua maioria partem de histórias pessoais, que geram textos dramatúrgicos encenados como espetáculos.

Em publicação recente, Óscar Cornago defende que "a evolução da arte moderna pode ser entendida como a busca por um diálogo cada vez mais estreito com uma realidade não intelectualizada, em um tempo em que o excesso de ficções mostra

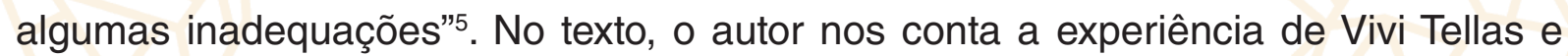

3 FISCHER-LICHTE, Erika. "Reality and Fiction in Contemporary Theatre". In: BOROWSKI, Mateusz e SUGÍERA, Malgorzata. Fictional realities/ real fictions. Neweastle, Cambridge Scholars Publishing, 2007, p. 13.

4 "In the 60s, the focus shifted from the fictional to the real without the tension diminishing. It was not only performance art but also theatre artists like Jerzy Grotowski who emphasized the real within a performance. (...) Grotowski reversed the relationship between actor and character/role, between the real and the fictional. He defined the fictional role as an instrument for achieving a particular goal, not as the end of the actors' effort. Like a surgeon uses his scalpel, the actor is required to use the role as a tool for dissecting himself."- Todas as traduções foram feitas pela autora. (FISCHER-LICHTE, 2007, p.14)

5 "La evolucion del arte moderna puede entenderse como la búsqueda de un diálogo cada vez más estrecho con una realidad no intelectualizada, al tiempo que el exceso de ficciones acusa ciertas insuficiencias".. CORNAGO, 
seu "Biodrama. Sobre la vida de las personas", um projeto que tem início em 2002, desenvolvido no Teatro San Martin de Buenos Aires, onde nove diferentes diretores/ diretoras foram convidados a desenvolver espetáculos baseados na vida de moradores da Argentina. Para Cornago foi um projeto que, além de muito bem sucedido, indicou "novos rumos para a criação cênica em sua busca por uma maior carga de realidade".

No teatro paulistano, alguns dos exemplos mais discutidos de uso da autobiografia são: Luis Antonio - Gabriela (2010), de Nelson Baskerville, Ficção (2012), de Leonardo Moreira com a Cia Hiato e Festa de Separação, um Documentário Cênico (2012), de Janaina Leite e Luis Fernando Marques.

O primeiro é a história de um garoto homossexual que apanhava do pai, que pretendia que ele se "curasse" da homossexualidade. Ele parte para a Espanha, onde se torna Gabriela, uma travesti-cantora de shows de boates, e lá morre de AIDS. É a história real do irmão do diretor do espetáculo.

Quanto ao trabalho da Cia Hiato, fragmentos de história pessoal de seis atores transformam-se no espetáculo Ficção, composto por seis solos. Resumo três deles. Thiago Amaral e seu pai estiveram rompidos durante anos e, em seu solo (Ficção\#1) $o$ ator coloca o pai em cena para que os dois encenem/atuem/vivam um processo de reconciliação. A presença de pessoas da família estende-se para outras duas cenas de Ficção: Aline Filócomo convoca a irmã para contracenar com ela (Ficção\#2) e Maria Amélia Farah traz para o palco o filho de um ano para fazer o percurso vital invertido e revisitar a morte imaginária da mãe (Ficção \#4) .

Já Festa de separação trata do rompimento real do casal Janaína Leite e Felipe Teixeira Pinto, depois de sete anos de relação. As sete festas - gravadas e documentadas - que ambos fizeram para ritualizar a separação constituem o eixo narrativo do trabalho, que entrelaça as linguagens do teatro e do documentário.

Incluo aqui outros dois criadores que, em certo sentido, trabalham na mesma direção: Antonio Abujamra e Denise Stoklos. E começo dizendo criadores, sem especificar esse ou aquele trabalho de cada um, como fiz acima, pois acredito que as experiências de vida de ambos sempre marcaram seus espetáculos. Pode-se dizer de

Óscar. "Biodrama. Sobre El teatro de la vida y la vida del teatro. LatinAmerican Theatre Review, (39):1, 2005, p.1. 6 CORNAGO, 2005, p.1-27

7 “(...) nuevos rumbos de la creación escénica en la búsqueda de una mayor carga de realidad”. CORNAGO, 2005, P. 1 8 Fica uma pergunta aos criadores de Ficção: por que esses espetáculos mantiveram seus títulos de "solo" se, em cena, havia a presença física de outros personagens/outras pessoas que faziam parte ativa da narrativa? 
Antonio Abujamra que todos os espetáculos que fez como ator trouxeram fortes referências pessoais, até chegarmos a $A$ Voz do Provocador, espetáculo no qual tudo o que faz é contar suas histórias, sua trajetória de vida, aliando e combinando experiências pessoais e profissionais. E sobre Denise Stoklos, pode-se afirmar que seus espetáculos expressam seu diálogo pessoal com obras de outros artistas, como Louise Bourgeois (Louise Bourgeois - Faço, Desfaço, Refaço/2000), Henri Thoreau (Desobediência Civil/1997) e Jorge Luis Borges (Elogio/1995), por exemplo. Quando realizou textos de própria autoria, como Casa (1990), na versão apresentada em NY, Stoklos trouxe seus dois filhos, na época ainda crianças, para contracenarem com ela ${ }^{9}$.

O que se pode observar, nos exemplos mencionados, é que a presença de "pessoas reais" parece surgir como um tipo de garantia para a realidade/veracidade da história apresentada, seja por meio da presença física de não-atores, seja através de fotos, documentos, gravações em áudio ou imagens. Dessa forma, diferentes gerações, diferentes propostas, diferentes estéticas e diferentes técnicas de interpretação trabalham, a partir de um material pessoal, para tentar espelhar as vidas e o mundo. Os criadores se inventarem a cada espetáculo, em cada espetáculo.

Se o uso do material autobiográfico no teatro pressupõe sempre uma história real de uma pessoa real, o que é o fascinante ato de contar histórias? Walter Benjamin, em seu já clássico O Narrador nos diz que "a arte de narrar está em vias de extinção" e que "são cada vez mais raras as pessoas que sabem narrar devidamente"10. Isso porque estaríamos privados da faculdade de intercambiar experiências. Segundo Benjamin, o narrador é aquele capaz de "retirar da experiência aquilo que nos conta: sua própria experiência ou a relatada pelos outros. E incorpora as coisas narradas à experiência de seus ouvintes."11 A experiência que o narrador compartilha é sua própria experiência, a experiência viva de seu tempo e de seus habitantes, que se transforma a cada vez que a história é contada.

9 Susan Sontag defende que o diário, ou seja, a prática do registro diário de pensamentos, experiências, vivências, desejos, enfim, das anotações pessoais registradas a cada dia, oferece não apenas a possibilidade de criar um "eu" (self) como também a de expressar esse "eu", de não apenas registrar a vida cotidiana mas de oferecer uma alternativa a ela. Será que podemos extender esse pensamento para espetáculos que fazem uso da autobiografia, de anotações e histórias pessoais? SONTAG, Susan, "To stand still is to fall away from truth," Guardian 14, September 2006, p. 7-11.

10 BENJAMIN, Walter. "O Narrador". In: Obras Escolhidas - Magia e Técnica, Arte e Política. Editora Brasiliense, 1996. P. 197

11 BENJAMIN, 1996, p. 201 
A questão da experiência me interessa especialmente, pois acredito que lança luz sobre o uso da autobiografia no teatro, quando um texto ou um espetáculo partem de uma experiência pessoal. Talvez esteja nessa experiência real a potencial relação que o narrador-artista estabelece com o ouvinte-espectador. Se as condições para a existência do narrador desapareceram, já que não existe mais a possibilidade de que a experiência transmitida seja comum ao narrador e ao ouvinte, acredito que no relato da experiência pessoal pode se projetar uma nova possibilidade de partilha. Pode-se imaginar que cada memória pessoal chame outra história e, por isso, cada texto autobiográfico pode ser infinito em sua multiplicação de histórias e sentidos, permitindo que narrador e ouvinte participem de um fluxo comum e vivo, de uma história aberta a novas propostas e ao fazer junto. Não seria esse um dos principais desejos do teatro, que suas obras não apenas sejam vistas, apreciadas, entendidas, mas que levem o espectador a pensar em sua própria vida, relacionando-a de maneira pessoal à vida do outro?

Acredito que o uso da autobiografia seja um meio de se alcançar essa qualidade. $\mathrm{E} o$ ator que conta sua história, da maneira que escolher contá-la, torna-se um criador de si mesmo, contando e recontando, criando e recriando suas histórias, seu passado, seu futuro. Nesse sentido, talvez o uso da autobiografia seja uma busca da "aura perdida" do teatro. ${ }^{12}$

Giorgio Agamben dialoga com Walter Benjamin a respeito da experiência. $\mathrm{Na}$ abertura de seu texto Infância e História, Destruição da Experiência e Origem da História, afirma que a experiência "não é mais algo que nos seja dado fazer. [...] o homem contemporâneo foi expropriado de sua experiência, aliás, a incapacidade de fazer e transmitir experiências talvez seja um dos poucos dados certos de que disponha sobre si mesmo"13. Já nesse início de texto, vemos que Agamben concorda com Benjamin ao afirmar que a destruição da experiência - experiência entendida como elemento fundamental para a arte de fazer e contar histórias que equivale ao intercâmbio de experiências - não deve ser apenas deplorada, mas, acima de tudo, constatada. "Pois talvez se esconda, no fundo dessa recusa aparentemente disparatada, um grão de sabedoria no qual podemos adivinhar, em hibernação, o germe de uma experiência futura."14 Ao retomar "o programa benjaminiano da filosofia que vem"15

12 BENJAMIN, 1996. p. 165-196

13 AGAMBEN, 2005, p. 21

14 AGAMBEN, 2005, p. 23

15 AGAMBEN, 2005, P. 23 
e a tarefa do historiador materialista capaz de fundar um outro conceito de tempo, Agamben pensa a possibilidade de uma nova narratividade.

A Narratividade, aqui ligada ao uso do material pessoal no teatro, ratifica a ideia da experiência como algo particular e subjetivo e, ao mesmo tempo, sugere que no contato com a experiência do outro o espectador possa de alguma maneira revivê-la, compartilhá-la, torná-la própria, produzindo seu próprio saber.

Em seu texto Notas sobre a experiência e o saber da experiência ${ }^{16}$, Jorge Larrosa Bondía também discute a ideia de Benjamin sobre a destruição da experiência. Buscando o sentido da palavra em diversas línguas, ele nos traz o espanhol "o que nos passa", o português "o que nos acontece", o francês "ce que nous arrive", o italiano "quello que nos sucede" e o inglês "that what is happening to us". E se essas são as definições da experiência em várias línguas, então ela é o que nos passa, o que nos acontece, o que nos toca e não o que se passa, o que acontece ou o que toca.

Depois de discutir a experiência e a destruição da experiência, que credita à falta de tempo e ao excesso de opinião, de informação e de trabalho, Bondía segue investigando quem é o sujeito da experiência, retomando os sentidos da palavra nas diversas línguas, para concluir:

Se escutamos em espanhol, nessa língua em que a experiência é 'o que nos
passa', o sujeito da experiência seria algo como um território de passagem,
algo como uma superfície sensível que aquilo que acontece afeta de
algum modo, produz alguns afetos, inscreve algumas marcas, deixa alguns
vestígios, alguns efeitos. Se escutamos em francês, em que a experiência é
"ce que nous arrive", o sujeito da experiência é um ponto de chegada, um
lugar a que chegam as coisas, um lugar que recebe o que chega e que, ao
receber, Ihe dá lugar. E em português, em italiano e em inglês, em que a
experiência soa como 'aquilo que nos acontece, nos sucede', ou "happen
to us", o sujeito da experiência é sobretudo um espaço onde têm lugar os
acontecimentos. ${ }^{17}$

Nesse sentido, o sujeito é entendido como território de passagem, ponto de chegada ou espaço do acontecer que se define por sua passividade, por sua disponibilidade e sua abertura. "Por isso é incapaz de experiência aquele que se põe, se opõe, se impõe, ou se propõe, mas não se ex-põe."18

16 BONDÍA, Jorge Larrosa. Notas sobre a experiência e o saber de experiência. In: Conferência proferida no I Seminário Internacional de Educação de Campinas/ Leituras SME. Campinas: Rede Municipal de Educação de Campinas/FUMEC, 2001, p.19-28.

17 BONDÍA, 2001, p. 24.

18 BONDÍA, 2001, p. 25. 
Já o saber da experiência diz respeito ao como respondemos àquilo que nos acontece, aos sentidos que somos capazes de fazer nascer ou aos não-sentidos. $O$ saber da experiência é, portanto, pessoal, particular e pertence somente àquele que se deixou atravessar pela experiência e por seu fazer. "Trata-se de um saber que revela ao homem concreto e singular, entendido individual ou coletivamente, o sentido ou o sem-sentido de sua própria existência, de sua própria finitude. Por isso, o saber da experiência é um saber particular, subjetivo, relativo, contingente, pessoal."19

Ao tratar da autobiografia no teatro em Atuar de Verdade, a Confissão como Estratégia Cênica ${ }^{20}$, Óscar Cornago trabalha um outro lado dessa experiência particular e subjetiva. Analisando a confissão, fala da importância da presença física do artista como ponte entre o que foi e o que é, e refere-se à palavra como ato físico da memória. Com a presença do ator/artista se faz presente o passado a partir do aqui e agora da palavra, como esse ato físico da memória. Nesse caso, a palavra dita se faz visível como uma ação a mais. Constrói-se, assim, uma ponte que vai desde o presente cênico desenvolvido frente ao público até o passado feito presente através das histórias que se contam, experiências, recordações, medos e sonhos. É nesse contexto - o da presença física do artista e da palavra como ato físico da memória que Cornago cita o cineasta Jean-Luc Godard, quando diz que "a verdadeira condição do homem é a de pensar com suas mãos"21. Entendida a partir do contexto da performance, a reflexão de Godard nos faz pensar que a autobiografia, trabalhada cenicamente, é uma forma de pensar com o próprio corpo, ou seja, a constante criação de um "eu" em cena é um processo performativo.

O uso da autobiografia no teatro tem relação íntima com o que Michael Kirby chama de autoperformance que, segundo o ensaísta, é um trabalho criado e interpretado pela mesma pessoa a partir de um material pessoal, que normalmente assume a forma de um monólogo, mas nem sempre e não necessariamente. ${ }^{22}$

19 BONDÍA, 2001, p. 26.

20 CORNAGO, 2009, p. 99-111.

21 CORNAGO, 2009, p. 106

22 KIRBY, Michael. The Drama Review: TDR, Vol. 23, No. 1, Autoperformance Issue (March, 1979). "An Introduction". O texto de Kirby é: "'Autoperformance' is a word we have coined to refer to presentations conceived and performed by the same person. Although they are often solo performances, this is not a defining characteristic. (...) 'Autoperformance' also refers to the autobiographical aspects of these works. Sometimes this personal material is obvious and explicit - as in Rumstick Road, performed by Spalding Gray and dealing with his mother's suicide. At other times they are unapparent or unemphasized. One might assume, however, that some sort of autobiographical material is always present in an autoperformance." 
O "material pessoal" a que Kirby se refere pode assumir diferentes formas, mas sempre parte da autobiografia do criador. Autobiografia aqui entendida não apenas como sequência de informações sobre determinada pessoa, mas, acima de tudo, o modo como essa pessoa viveu cada um dos fatos, como produziu experiências e criou sentidos a partir de cada momento. O uso da autobiografia como desdobramento da presença do real no teatro está no centro da definição de Kirby.

\section{Spalding Gray, um exemplo de autobiografia no teatro}

"Para mim não existe nada maior, mais amplo, que o pessoal quando é bem comunicado." Spalding Gray ${ }^{23}$

Na intenção de contextualizar as reflexões anteriores, apresento agora um pouco da trajetória e do trabalho do ator-performer Spalding Gray, referência maior quando se fala de autobiografia no teatro. Para começar a falar sobre ele, trago uma citação de Marvin Carlson, que afirma:

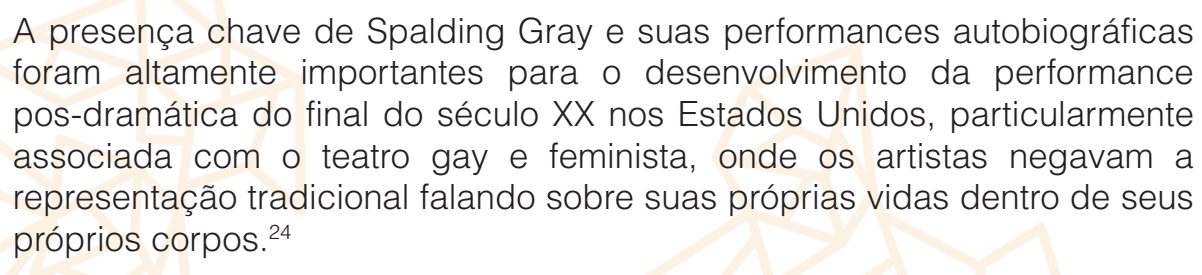

Até se juntar ao The Performance Group, em 1970, grupo dirigido por Richard Schechner, Spalding Gray passa por quatro anos de formação "tradicional”25 em interpretação e direção, cinco anos atuando no "teatro regional"26 e em peças off-Broadway. Comentando o modo de trabalho do grupo, Gray menciona uma questão importante até hoje:

Foi o método de trabalho de Richard Schechner com The Performance Group que me permitiu deixar os personagens e voltar a mim mesmo. O nome, The Performance Group, foi escolhido para enfatizar a diferença entre "atuar" e

23 "For me there is nothing larger than the personal when it is communicated well". GRAY, SPALDING, Performing Arts Journal, 1982 n.6:1 p.46-49

24 "The key presence of Spalding Gray and his autobiographical performances were highly important in developing a late twentieth century tradition of post-dramatic performance in the United States, particularly associated with feminist and gay theatre, in which artists denied traditional representation by talking about their own lives within their own bodies". CARLSON, 2013, p. 13.

25 A formação "tradicional" a que Spalding Gray se refere é seu treinamento stanislavskiano.

26 Teatro regional/regional theatre ou resident theatres são companhias profissionais ou semi-profissionais que produzem suas proprias temporadas e frequentemente apresentam trabalhos inovadores, novos autores, novos criadores, que não necessariamente têm o apelo para se tornarem um espetáculo da Broadway. 
"performar", uma distinção difícil e frequentemente confusa porque os dois sempre parecem se misturar, se colocar um contra o outro. ${ }^{27}$

Com o TPG, Spalding participa de cinco produções - Commune (1970), criação do grupo, The Tooth of Crime (1972), de Sam Shepard, Mãe Coragem (1975), de Bertolt Brecht, Cops (1978), de Curtis Fox e O Balcão (1979), de Jean Genet, todas sob a direção de Richard Schechner. A partir de 1974, começa a desenvolver um trabalho bastante particular com Elisabeth LeCompte, outra integrante do TPG, que resulta na trilogia Three Places in Rhode Island, nome dado a posteriori, quando da apresentação conjunta das três peças feitas separadamente - Sakkonett Point/1975, Rumstick Road/1977 e Nayatt School/1978. Os títulos referem-se a lugares da infância de Spalding Gray: uma cidade onde passa férias de verão, o nome da rua onde morou e o nome de sua escola. As três peças tratam do tema da perda, não apenas a perda que Spalding viveu com o suicídio da mãe, mas o sentimento de perda em geral.

Vale lembrar que o processo de laboratórios, improvisações, ensaios e apresentações de Three Places in Rhode Island levou à formação do The Wooster Group e à saída de Richard Schechner do grupo.

Durante os dez anos com o Wooster, Spalding Gray faz importantes descobertas sobre seu papel como ator. Em primeiro lugar, nota que interpretou as teorias de Schechner como um passe livre para fazer o que quisesse e ser quem era, acreditando que o texto daria estrutura para essa liberdade. Visto como uma onda que podia surfar à sua própria maneira, o texto, para Spalding, deve dar ao espectador a liberdade de fazer as conexões que quiser e puder, a partir de sua associação às ações cênicas. Portanto, o ato criativo também deve acontecer a partir do público.

Essa foi uma descoberta importante para mim e me levou a duas coisas. Primeiro, comecei a questionar completamente a ideia de representar um personagem. Isso começou a acontecer durante a produção de Mãe Coragem do The Performance Group. Nessa produção, desenvolvi o personagem de Swiss Cheese sem nenhum pensamento consciente sobre Brecht e o que ele talvez esperasse daquele personagem. Eu não pensei sobre a peça mas, ao invés disso, fiz o personagem a partir das minhas necessidades imediatas e deixei o texto me dar a estrutura para essas ações pessoais. O público parecia gostar e entender o meu Swiss Cheese e fazia conexões claras e integradas entre o personagem e o texto.

Segundo, eu descobri que texto e ação poderiam existir separadamente e serem entendidos. Isso levou à maneira com que construímos nosso primeiro trabalho original, Sakonnet Point. Fez nascer em mim o desejo

27 "It was Richard Schechner's method of working with The Performance Group that allowed me to drop the roles and come back to myself. The name, The Performance Group, was chosen to emphasize the difference between 'acting' and 'performing', a difficult and often confusing distinction because the two always seemed to intermingle, to play off one another". GRAY, 1979, p. 31-42. 
de criar uma narrativa aberta feita de ações pessoais e ver se o público seria capaz de juntar todas elas. Estava mantendo a mesma dialética, mas abandonando o texto e permitindo que a mente de cada pessoa do público criasse seu próprio texto. Eu era o personagem, e o texto em que eu tinha que me encaixar estaria na imaginação do público. Essa era minha ideia de participação do público. ${ }^{28}$

Ironicamente, diz Spalding, foi a descoberta desse estilo pessoal de trabalho que o distanciou do grupo, aproximando-o de um trabalho feito por ele/para ele. Em 1978, deixa o The Wooster Group e a figura que nasce dessa ruptura até hoje encanta, emociona e perturba quem quer que dela se aproxime. O performer passa a se apresentar apenas com uma mesa, um copo de água, poucos objetos, algumas projeções de video e contar suas histórias a públicos diferentes ao longo dos vinte e cinco anos seguintes. É um narrador, como entende Walter Benjamin, um contador de histórias capaz de intercambiar experiências, aquele que "retira da experiência o que ele conta: sua propria experiência ou a relatada pelos outros. E incorpora as coisas narradas à experiência de seus ouvintes". Essa capacidade de relatar, narrar, relacionar-se e se associar à vida é que garante ao contador de histórias uma aura incomparável. Não mais fatos ou eventos per se, mas histórias que nos permitem contar histórias. Essa é a aura do narrador, a aura de Spalding Gray. O poder de suas histórias vem do convite que faz ao espectador de interpretá-las como quiser e de incorporar às coisas narradas sua própria experiência.

Em conversa com o público após a apresentação de Rumstick Road, no American Place Theatre, ouvimos as mais diversas manifestações, a maioria de pessoas muito emocionadas com o que tinham presenciado. Em determinado momento do debate, valendo-se da multiplicidade de reações que causou, Spalding lembra que o espetáculo traz uma narrativa aberta que joga o espectador para seus próprios pensamentos e associações. Uma das espectadoras diz que ficou confusa ao ver um mesmo ator interpretar dois personagens, o médico e a mãe (Ron Vawter fazia os dois persona-

28 "This was an important discovery for me and led me to two points. First, I began to question the whole idea of enacting a role at all. This began to happen during The Performance Group's production of Mother Courage. In this production, I developed the role of Swiss Cheese without any conscious thought about Brecht and what he might have wanted. I did not think about the play but, rather, made the role out of my immediate needs and let text supply the structure for these personal actions. The audience seemed to enjoy and understand my Swiss Cheese and to make clear and integrated connections between that role and the text. Second, I discovered that text and action could exist separately and be understood. This led to the way in which we constructed our first original work, "Sakonnet Point". It led me to the desire to create an open narrative of personal actions and to see if the audience could, and would, tie them together. It was maintaining the same dialectic, but dropping the text and allowing the mind of each audience member the chance to create its own text. I was the role, and the text into which I fit was to be within the audiences' imaginations. This was my idea of audience participation". GRAY, 1979, p. 31-42. 
gens), e foca seu discurso em como "recebeu" as cenas e o espetáculo. Gray reage e diz que quer esclarecer uma questão de terminologia em relação à palavra "receber":

Nesse caso, nessa peça em particular, você tem que ser reponsável por ir ao encontro dela e, então, eu estou recebendo de você. Porque não existem atores nessa peça. Nós somos performers. Aquele é Ron Vawter, ele não está interpretando, ele está fazendo improvisações, ele não está tentando representar um personagem específico que ele quer dar a você. O que a gente pede de vocês é que, ao invés de serem receptores, encontrem um centro em vocês e venham até a gente e também afetem o espetáculo tendo suas próprias opiniões sobre a peça. ${ }^{29}$

Essa troca com o público vai acompanhar Spalding sempre. Quando pensa em um novo espetáculo, ele começa apenas com um esboço das histórias e situações que quer desenvolver, e passa a fazer apresentações para uma pessoa ou mesmo em espaços públicos para plateias interessadas. Essas apresentações são gravadas para que ele possa ouvi-las depois, para descobrir e determinar "como posso torná-las um pouco mais dramáticas e engraçadas justapondo uma pequena hipérbole aqui, jogando um pouco com ela ali"30. E assim segue acompanhando as reações do público, descobrindo formas, definindo histórias, até que, depois de trinta ou quarenta apresentações, chegue ao formato final do espetáculo. Já o texto a ser publicado, esse pode levar até cinco anos para chegar às livrarias.

A experiência com Three Places in Rhode Island foi determinante para fazer nascer o performer Spalding Gray, o contador de histórias, aquele que vive sua vida sempre com o distanciamento de quem pretende usar cada gesto ou fala em seu próximo espetáculo. Ou até mesmo incorporar novas falas a um espetáculo já pronto, tornando-o vivo e permeável ao que the acontece a qualquer momento, em qualquer lugar, na tentativa de inventar "um tempo de agora, caracterizado por sua brevidade."31.

A afirmação de Spalding Gray sobre sua forma de escrever/construir textos ecoa claramente as ideias de Schechner, quando esse pioneiro dos estudos da performance

\footnotetext{
29 Esse debate entre o público e Spalding Gray aconteceu no American Place Theatre após a apresentação de "Rumstick Road" e está documentado em uma fita do arquivo do The Wooster Group a que tive acesso para escrever esse trabalho quando estive em NY. O texto apresentado aqui é uma transcrição direta das palavras de Spalding Gray, e mantive a informalidade de sua fala. "You should take responsability for, in this case, in this particular piece, you're going out to it, so l'm receiving from you. Because there are no actors in the play. We are performers. That's Ron Vawter, he's not acting, he's doing improvs, he's not attempting to reenact a particular role in which he is sending out to you. So what we ask of you instead of being all recivers, is to find a center in yourself and come out and also affect the piece by having your opinion on the piece".
}

30 "how I can make it a little more dramatic and funny by juxtaposing a little hyperbole here and play with it a little bit there". SCHECHNER, 2002, p. 154-174.

31 BENJAMIN, 1996, p. 8. 
diz que ela pode ser entendida em relação a três ações: being/sendo, doing/fazendo, showing doing/mostrar fazendo e explaining "showing doing"/explicar "mostrar fazendo"32.

Marvin Carlson, por sua vez, afirma que a performance é sempre "emoldurada no modo da autorreflexividade", pois aquele que mostra é sempre aquele que faz. ${ }^{33}$ “Este princípio do 'mostrar fazendo' que Schechner compara ao efeito brechtiano de distanciamento, aparece como elemento fundante de toda performance."34

Retomando as ideias de Schechner, Eelka Lampe fala muito claramente sobre o trabalho dos performers e a tensão que mantém entre o real e a ficção:

Na performance, a qualidade artística depende de quão bem sucedidos são os performers em manter a tensão ou o equilíbrio dialético entre o real e o fictício, o 'eu' e o 'não-eu'. ${ }^{35}$

Escolhas pessoais entram em jogo, entram em cena. Não se trata mais de um personagem a ser interpretado por um ator, mas de um ator jogando com diferentes personagens a partir dele mesmo. Não mais a história (supostamente) conhecida e verdadeira a ser apresentada ao espectador, mas sim a história do tempo presente do performer em relação consigo mesmo, com suas criações e com seu público.

Isso nos devolve à Josette Féral, que reivindica que "o processo performativo age diretamente no coração e no corpo da identidade do performer, questionando, destruindo, reconstruindo seu eu, sua subjetividade sem a passagem obrigatória por uma personagem"36

O performer vive sempre no momento presente da performance e esta permanece em constante transformação. No caso de Spalding Gray, até sua morte em 2004. Após sofrer um sério acidente de carro em junho de 2001, com a perna direita praticamente imobilizada e uma fratura de crânio que o obriga a uma grave cirurgia para colocação de placa de titânio na cabeça e lhe deixa uma grande cicatriz na testa, o performer mergulha em grave depressão. Oliver Sachs é um dos profissionais que participam do tratamento a que o artista se submete. O famoso neurologista do NYU Medical Center afirma que, em várias ocasiões, Spalding Gray referiu-se à sua morte como "um suicídio criativo". Mais de uma vez o performer sugeriu ao terapeuta que

32 SCHECHNER, 2007, p. 28-51

33 CARLSON, 1996, p. 189

34 FÉRAL, 2009

35 "In performance, artistic quality depends on how successfully performers maintain the tension or the dialectical balance between the actual and the fictive, the 'me' and the 'not me'." LAMPE, 1988, p. 170-190.

36 FÉRAL, 2009 
as entrevistas que faziam deveriam ter como ápice um "dramático e criativo suicídio". E Sacks completa: "Eu fiz de tudo, fiz o possível para dizer que ele seria muito mais criativo vivo do que morto."37

Em 10 de fevereiro de 2004, Spalding Gray desaparece e em março seu corpo é encontrado no East River. No dia anterior a seu desaparecimento tinha levado um dos filhos para ver Big Fish, de Tim Burton. O personagem central do filme é um contador de histórias que está morrendo na cama de um hospital ao lado do filho, que lhe conta a história de sua fuga da internação. No caminho de fuga, o narrador encontra todos os personagens de suas histórias, até se jogar no rio e transformar-se em um enorme peixe, o Big Fish das histórias de pescador, conhecidas por exagerarem ou mesmo inventarem os fatos. Na cena final do filme vemos o verdadeiro enterro do pai, no qual estão presentes todos aqueles de quem contou as histórias, o que sugere que elas eram verdadeiras. Nas palavras finais do filme, "um homem conta uma história tantas e tantas vezes que se torna essa história. E assim é imortal." A viúva de Spalding Gray, Kathie Russo, conta que Spalding Gray chorou depois de assistir a Big Fish. E acrescenta: "Eu acho que ele lhe deu permissão para morrer"38.

Sua morte nos faz pensar que aquilo que Rilke identificou em Cuadernos de Malte como a dificuldade e a raridade de se ter uma vida própria, pessoal, quase tão rara "como uma morte própria", foi alcançado por Spalding em sua trajetória como performer e em seu "suicídio criativo." Elas dizem muito sobre a capacidade que temos, e que podemos despertar em nós mesmos e nos outros, de fazer infinitas associações, de contar e recontar histórias, descobrindo ou inventando novos sentidos para a vida. Uma capacidade que precisa ser constantemente acordada em cada um de nós, e que me leva a citar Valéry:

\begin{abstract}
A observação do artista pode atingir uma profundidade quase mística. Os objetos iluminados perdem os seus nomes: sombras e claridades formam sistemas e problemas particulares que não dependem de nenhuma ciência, que não aludem a nenhuma prática, mas que recebem toda sua existência e todo o seu valor de certas afinidades singulares entre a alma, o olho e a mão de uma pessoa nascida para surpreender tais afinidades em si mesmo, e para as produzir. ${ }^{39}$
\end{abstract}

37 "On several occasions he talked about what he called 'a creative suicide.' On one occasion, when he was being interviewed, he thought that the interview might be culminated with a 'dramatic and creative suicide.'" e "I was at pains to say that he would be much more creative alive than dead". WOOD, Gaby (2004-12-26), Shades of Gray, The Observer.

38 "Vanishing Act" New York Magazine. "You know, Spalding cried after he saw that movie. I just think it gave him permission. I think it gave him permission to die". WILLIAMS, Alex (02 de fevereiro de 2004).

39 VALÉRY apud BENJAMIN, 1996, p. 220. 


\section{Bibliografia}

AGAMBEN, Giorgio, Infância e História, Destruição da Experiência e Origem da História. Ed. UFMG, 2005.

BENJAMIN, Walter. Obras Escolhidas - Magia e Técnica, Arte e Política. Editora Brasiliense, 1996.

BONDÍA, Jorge Larrosa. Notas sobre a experiência e o saber de experiência, Conferência proferida no I Seminário Internacional de Educação de Campinas, traduzida e publicada, em julho de 2001, por Leituras SME; Textos-subsídios ao trabalho pedagógico das unidades da Rede Municipal de Educação de Campinas/FUMEC, 2001, p.19-28.

CARLSON, Marvin. Performance: a critical introduction New York/London: Routledge, 1996.

CARLSON, Marvin. Some contemporary implications of the post-dramatic, Colóquio Pensar a Cena Contemporânea, Programa de Pós-Graduação Teatro - PPGT Universidade do Estado de Santa Catarina - UDESC, 2013 (no prelo)

CORNAGO, Óscar. Atuar de Verdade. A Confissão como Estratégia Cenica. Urdimento, setembro 2009. pags. 99-111

CORNAGO, Óscar. Bio-drama. Sobre El teatro dela vida y la vida del teatro. Latin American Theatre Review, (39):1, 2005,

DA COSTA, José. Irrupções do real no teatro contemporâneo. Subtexto, Belo Horizonte, n.6, dez 2009;

FÉRAL, Josette. Le réel à 'epreuve du théâtre. In FÉRAL, Josette. Théorie et pratique du théâtre. Au-delà des limites. Paris, L'Entretemps, 2011;

Performance e Performatividade: o que são os Performance Studies. MOSTAÇO, Edélcio; OROFINO, Isabel; BAUMGÄRTEL, Stephan; COLAÇO, Vera (Organizadores). Sobre Performatividade. Florianópolis: Editora Letras Contemporâneas, 2009. p. 49-86. FISCHERLICHTE, Erika. Reality and fiction in contemporary theatre. In BOROWSKI, Mateusz e SUGÍERA, Malgorzata, Fictional realities/real fictions. Newcastle, Cambridge Scholars Publishing, 2007.

FINTER, Helga. A teatralidade e o teatro. Espetáculo do real ou realidade do espetáculo? Notas sobre a teatralidade e o teatro recente na Alemanha. Teatro al Sur,n. 25, out. 2003.

GRAY, Spalding. Performing Arts Journal, 1982 n.6:1 pag.46-49.

About Three Places in Rhode Island, The Drama Review: TDR, Vol. 23, No. 1, Autoperformance Issue (March, 1979), pp. 31-42

GUMBRECHT, Hans Ulrich. Produção de Presença. O que o sentido não consegue transmitir. Trad. Ana Isabel Soares. RiodeJaneiro: Contraponto: Ed. PUC-Rio, 2010.

KIRBY, Michael. An Introduction, The Drama Review: TDR, Vol. 23, No. 1, Autoperformance Issue (March, 1979).

LAMPE, Eelka. Rachel Rosenthal Creating Her Selves, TDR, Vol. 32, No. 1 (Spring, 1988), pag. 170-190.

SONTAG, Susan, To stand still is to fall away from truth, The Guardian, 14 September 2006: p. 7-11 SCHECHNER, Richard My Art in Life: Interviewing Spalding Gray, TDR, Vol. 46, No. 4 (Winter, 2002), pp. 154-174

SCHECHNER, Richard What is Performance? in Performance Studies: An Introduction New York, Routledge, 2007, pags. 28-51

WILLIAMS, Alex (02 de fevereiro de 2004). Vanishing Act, New York Magazine.

WOOD, Gaby (26 de dezembro de 2004), Shades of Gray, The Observer. 